Revue Revue de l'histoire des religions
de I'histoire des religions
$3 \mid 2013$
Varia

\title{
Joseph NAVEH, Studies in West-Semitic Epigraphy. Selected Papers
}

The Hebrew University Magnes Press, Jerusalem, 2009, 544 p., 49,00 \$, ISBN 978-965-493-387.

Jean-Marie Husser

\section{OpenEdition \\ Journals}

Édition électronique

URL : http://journals.openedition.org/rhr/8128

DOI : $10.4000 /$ rhr.8128

ISSN : $2105-2573$

Éditeur

Armand Colin

Édition imprimée

Date de publication : 1 septembre 2013

Pagination : 403-405

ISBN : 978-2200928650

ISSN : 0035-1423

\section{Référence électronique}

Jean-Marie Husser, "Joseph NAVEH, Studies in West-Semitic Epigraphy. Selected Papers ", Revue de I'histoire des religions [En ligne], 3 | 2013, mis en ligne le 04 octobre 2013, consulté le 22 septembre 2020. URL : http://journals.openedition.org/rhr/8128 ; DOI : https://doi.org/10.4000/rhr.8128

Ce document a été généré automatiquement le 22 septembre 2020.

Tous droits réservés 


\section{Joseph NAVEH, Studies in West-Semitic Epigraphy. Selected Papers}

The Hebrew University Magnes Press, Jerusalem, 2009, 544 p., 49,00 \$, ISBN 978-965-493-387.

Jean-Marie Husser

\section{RÉFÉRENCE}

Joseph NAVEH, Studies in West-Semitic Epigraphy. Selected Papers, The Hebrew University

Magnes Press, Jerusalem, 2009, 544 p., 49,00 \$, ISBN 978-965-493-387.

1 À l'initiative de Shaul Shaked et Matthew Morgenstern, les éditions Magnes de l'Université hébraïque de Jérusalem ont publié un recueil de cinquante-quatre articles du grand épigraphiste israélien Joseph Naveh, couvrant plus de trente années de recherche, de 1967 à 2003. Même si certains articles ont perdu de leur actualité une fois apaisés les débats dans lesquels ils s'inscrivaient, on apprécie de voir ainsi réunis les jalons d'une longue carrière de recherche en épigraphie ouest-sémitique. Grâce à une organisation thématique des articles, les spécialistes de la discipline ou les historiens du monde ouest-sémitique ancien pourront aisément suivre rétrospectivement des discussions qui se sont déroulées sur plusieurs années et retrouveront avec plaisir quelques articles décisifs sur la lecture et/ou la datation de documents devenus des fondamentaux de la recherche. Le recueil permet également de profiter de l'érudition de l'auteur grâce à plusieurs index en fin de volume : un index général comportant lieux, thèmes et auteurs modernes; un index des noms propres anciens ; un index des références, essentiellement dans la Bible et la littérature juive ancienne. Un glossaire enfin renvoie aux mots donnant lieu à discussion dans les différents articles.

2 Ces articles ont été publiés majoritairement dans IEJ (Israel Exploration Journal), 'Atiqot, BASOR (Bulletin of the American School of Oriental Research). Le texte en est reproduit par procédé photographique, de sorte que le volume comporte une double pagination, celle des publications originales et la sienne propre. On dispose ainsi des photographies et 
fac-similés de plusieurs inscriptions, ainsi que de tableaux comparatifs de différentes graphies réalisés par l'auteur. En plus de la table des matières, des remerciements adressés aux éditeurs donnent les références précises des publications originales.

Il est évidemment impossible de rendre compte ici de la totalité des articles proposés dans cet ouvrage. Comme l'A. s'en explique dans une courte préface, ils ont été répartis en six sections d'inégale importance en fonction de leur contenu, des thèmes traités ou des domaines linguistiques concernés.

4 La première section réunit huit articles traitant de l'histoire des écritures ouestsémitiques, de l'hébreu au mandéen. Cinq de ces articles $\left(n^{\circ} 1,2,6,7,8\right)$ développent des idées reprisent dans Early History of the Alphabet, an Introduction to West Semitic Epigraphy and Palaeography (Jerusalem-Leiden, 1982). Dans un article de 1995 (n 5), l'A. s'appuie sur les inscriptions de l'île de Failaka pour soutenir que les caractéristiques graphiques de l'araméen lapidaire qui se répandit à la période achéménide (écriture allongée, maintien des graphies anciennes du aleph, du waw, du zaïn et du yod) furent en usage jusqu'au début $\mathrm{du} \mathrm{II}^{\mathrm{e}} \mathrm{s}$. a.C., observation qui résout quelques problèmes de datation.

5 La deuxième section comporte trois articles traitant de la diffusion de l'alphabet ouestsémitique vers la Grèce archaïque ( $\mathrm{n}^{\circ}$ 9, 10,11). Dans ces écrits répartis entre 1973, 1987 et 1991, l'auteur défend sa théorie que ce passage de l'alphabet vers la Grèce archaïque s'opéra vers 1100 a.C. La troisième section est la plus consistante, avec une vingtaine d'articles consacrés à l'épigraphie araméenne d'époques diverses - incluant donc l'araméen ancien, l'araméen d'empire, mais aussi le nabatéen et le syriaque. Ces articles touchent à différents domaines, administratif, numismatique, funéraire, magique, géopolitique, etc. Certains ne sont que de brèves notes, telles ces deux pages publiées en 1967 dans IEJ ( $\mathrm{n}^{\circ}$ 21) dans lesquelles l'A. donnait, à partir du rapport préliminaire et des premières photographies publiées, une appréciation de la date de la fameuse inscription sur plâtre de Deir 'Alla, appréciation qui s'avéra par la suite être la bonne. D'autres sont plus substantiels, comme l'article publié en 1989 dans IEJ conjointement avec I. Eph'al ( $\left.{ }^{\circ} 28\right)$, qui assura définitivement la lecture et le commentaire de l'inscription d'Hazaël sur le frontail de cheval en bronze trouvé à Samos; ou encore, publiés et commentés en 1995 avec A. Biran, toujours dans IEJ (n²9), les deux fragments additionnels de l'inscription de Tel Dan trouvés l'année précédente. Ces pages fournissent en outre les photographies de tous les fragments de l'inscription et de son contexte archéologique.

6 La quatrième section comporte onze contributions à diverses questions d'épigraphie phénicienne, hébraïque, ammonite et philistine. Le matériel ici est le plus souvent très fragmentaire, constitué de graffiti, d'inscriptions sur céramique ou sur sceaux. Deux articles attirent l'attention, consacrés à la dédicace royale de Tel Miqne-Ekron et publiés respectivement en 1997 (IEJ) et 1998 (BASOR) ( ${ }^{\circ} 38$ et 39). Le premier notamment, fait en collaboration avec S. Gitin et T. Dothan, propose une étude approfondie de cette importante inscription qui documente le domaine philistin au viI s. et croise les sources assyriennes et bibliques.

7 La cinquième section réunit neuf articles plus éclectiques sur la provenance et la nature des inscriptions étudiées: graffiti rupestres nabatéens $\left(n^{\circ} 43\right)$, lampes d'époques variées ( $\left.n^{\circ} 45\right)$, manuscrit de Qumrân ( $\left.n^{\circ} 48\right)$, col de jarre inscrit du Jourdain $\left(n^{\circ} 49\right)$, dédicace d'époque byzantine ( $\left.n^{\circ} 50\right)$. Les thèmes abordés dans cet ensemble d'articles ne sont pas moins variés, allant des questions de graphie (séparation des mots, 
orthographe, translittération) $\left(\mathrm{n}^{\circ} 44,45,47,50\right)$ à la dimension religieuse des graffiti $\left(n^{\circ} 43\right)$, en passant par des questions d'onomastique $\left(n^{\circ} 46\right)$ et de poids et mesures $\left(n^{\circ} 49\right)$. Une sixième section enfin réunit sous le titre « Dubiosa » trois derniers articles $\left(n^{\circ} 52,53,54\right)$ dans lesquels l'A. contribue, à intervalles réguliers (en 1968, 1982, 1998), à l'assainissement du corpus épigraphique en débusquant les faux produits par le marché des antiquités, ou en demandant au moins un réexamen critique de l'authenticité de certaines pièces (1998).

Un ouvrage très riche donc, très représentatif de la recherche en ce domaine dans les dernières décennies. Il ne prétend bien évidemment pas apporter du nouveau, puisque tout a déjà été écrit, publié et discuté. On comprend néanmoins la double intention des éditeurs: mettre à la disposition des praticiens de l'épigraphie ouest-sémitique, des jeunes chercheurs notamment, une somme de discussions, de commentaires et d'érudition réunie en un seul volume, et aussi rendre un bel hommage à un maître incontesté en ce domaine.

\section{AUTEURS}

\section{JEAN-MARIE HUSSER}

Université de Strasbourg. 